\title{
The link between food and reproduction in aphidophagous predators: a case study with Harmonia axyridis (Coleoptera: Coccinellidae)
}

\author{
EDWARD W. EVANS and DERrick I. GUNTHER \\ Department of Biology, Utah State University, Logan, UT 84322-5305, USA; e-mail: ewevans@biology.usu.edu
}

Key words. Coccinellidae, Aphidophagous, diet, oviposition, predation, prey quality, reproductive strategy

\begin{abstract}
For polyphagous predators, the link between food consumption and reproduction is not always straightforward, and instead may reflect that even predators with very broad diets may have reproductive tactics that are tied to consumption of a restricted range of prey. We studied the consumption and use of two prey species for reproduction by the ladybird, Harmonia axyridis Pallas. This polyphagous predator feeds on both pea aphids [Acyrthosiphon pisum (Harris)] and larvae of the alfalfa weevil [Hypera postica (Gyllenhal)] that it encounters when foraging in alfalfa fields. When provided a diet of pea aphids or of alfalfa weevils and/or sugar water, females of $H$. axyridis laid eggs in large numbers only on the diet of aphids. Females laid no eggs on diets of weevils or sugar alone, and laid only small numbers of eggs when the two foods were provided together. When placed on a diet of aphids, females began laying eggs earlier, and laid more eggs altogether, when they had previously fed on weevils versus sugar water. The predators' consumption rates of aphids were greater than their consumption rates of weevils, and they produced less frass per mg of prey consumed on an aphid versus weevil diet. The predators searched more actively when maintained on a weevil versus aphid diet. Hence, lower rates of food intake and assimilation, and greater allocation of nutrients and energy to searching, appear to contribute to the reduced egg production of $H$. axyridis females that feed on weevils versus aphids. Alfalfa weevils are also less suitable prey than pea aphids for larval survival and development of $H$. axyridis. Thus, the differing responses of $H$. axyridis adults to these two prey types may reflect that these predators are well adapted in the linking of their feeding and reproductive behavi or.
\end{abstract}

\section{INTRODUCTION}

Most insect predators, including aphidophagous species, are generalist (polyphagous) species that consume multiple species of prey, often representing a wide variety of insects and related taxa (Hagen et al., 1999). Nonetheless, entomologists have recognized for many years that not all the prey consumed by a given species of predator are equally suitable as food. Thus, Hodek (1962; Hodek \& Honěk, 1996) developed the broad distinction between essential and alternative foods; the former support growth, development and reproduction, while the latter serve entirely or primarily as supplementary foods to maintain the predator temporarily in the absence of the former.

For adult predators, this distinction between prey types serves to highlight that the link between food consumption and reproduction may often be complicated, and may depend on qualities of both the predator and the prey. Ultimately these qualities may shape and reflect reproductive tactics of the predators, as even predators with very broad diets are likely to be to some degree specialized and carefully adapted in their reproductive behavior. This is captured well by Dixon's (2000) concept of nursery foods for insect predators, i.e., those prey that elicit active egg production and oviposition by predators and thereafter serve to ensure successful development of offspring. Dixon contrasts such prey with other prey (food prey) that the adult predators consume primarily to sustain themselves while seeking out patches of nursery prey at which to reproduce. The large variety of these food prey consumed by predators likely reflects that the predators often face food shortage in nature (e.g., Lenski, 1984; O’Neil \& Wiedenmann, 1987; Siddique \& Chapman, 1987; Beckman \& Hurd, 2003). Thus, they may be well adapted in the linking of feeding and reproductive behavior such that they exploit well the relatively rare opportunities for successful reproduction associated with discoveries of suitable patches of nursery prey.

Proximately, the extent to which a particular prey species serves as essential food in support of predator reproduction depends on key features such as how much of the prey the predator consumes (e.g., Bilde \& Toft, 1994), how well the predator can assimilate and utilize nutrients and energy upon consuming the prey (e.g., Wipperfürth et al., 1987; Bilde \& Toft, 1999; Bilde et al., 2000), and how much of what is assimilated is then allocated by the predator to reproduction (e.g., O'Neil \& Wiedenmann, 1987; Legaspi \& O’Neil, 1993; Nakashima \& Hirose, 1999; Vivan et al., 2003). In general, these features likely reflect not only basic nutritional qualities of the prey itself (e.g., Bilde \& Toft, 1999; Francis et al., 2001), but also properties of the predator as well. Aphidophagous insects provide good illustrations. For example, contact with body fluids of aphids may stimulate high rates of consumption (and subsequent reproduction) by aphidophagous ladybirds (Nakamuta, 1984). Similarly, ladybird species often vary widely in their abilities to assimilate and thrive upon consuming a given species of aphid prey, which may be protected chemically (e.g., Hodek, 1962; Blackman, 1967; see also Beck \& Toft, 2000). Furthermore, as suggested by Wipperfürth et al. (1987), predator physiology may be such that reproductive activity is triggered by consumption of particular species of prey. Even 
in cases where predators accumulate resources for reproduction during their immature development, they may be stimulated as adults to convert those resources into eggs by contact with particular prey (e.g., see discussion in Sadeghi \& Gilbert, 2000).

We study here the consumption and use of two prey species for reproduction by the predator, Harmonia axyridis Pallas. The predator is noteworthy in being especially polyphagous among aphidophagous Coccinellidae (see reviews by Hodek \& Honěk, 1996; Koch, 2003). Recently introduced to North America (e.g., see references in Kalaskar \& Evans, 2001), H. axyridis is now one of a dozen or so species of ladybirds that frequent alfalfa fields of northern Utah. These species feed especially on pea aphids [Acyrthosiphon pisum (Harris)] but prey also on the abundant larvae of the alfalfa weevil, Hypera postica (Gyllenhal) (Evans \& England, 1996; Evans, 2004). In previous studies of other members of this ladybird guild, it has been found that the aphid serves as an essential or nursery prey and the weevil serves as an alternative or food prey (e.g., Richards \& Evans, 1998; Evans et al., 1999, 2004). In the present study, we demonstrate that this is true for H. axyridis as well, and we investigate how much the difference in the predator's reproductive activity associated with the two prey types lies in differences in food consumption, assimilation, and/or allocation.

\section{METHODS}

\section{Egg production on differing diets}

Experimental individuals of $H$. axyridis were reared to adulthood in the laboratory from eggs laid by field-collected females; both the field-collected females and the larvae that they produced were fed a diet of pea aphids (raised on broad beans, Vicia faba L., in the greenhouse). For one to two weeks after emerging from the pupal stage, individuals were held at $15^{\circ} \mathrm{C}$ and $13 \mathrm{~L}: 11 \mathrm{D}$, and were provided pea aphids in excess. They were then placed together as female-male pairs in Petri dishes (diameter $9 \mathrm{~cm}$, and containing a small vial of water with a cotton wick). Individual pairs were assigned to receive one of four experimental diets $(\mathrm{N}=$ eight pairs per treatment): (1) pea aphids (of mixed ages, provided in excess), (2) alfalfa weevil larvae (also provided in excess as twelve fourth instars per day, collected originally from the field and maintained before use in a refrigerator on freshly cut stems of alfalfa), (3) sugar (the water vial was filled with a $15 \%$ sucrose solution, and was replaced throughout the experiment every two to three days), or (4) alfalfa weevil larvae + sugar (with these foods provided as in the previous two diets).

The experimental diets were provided to pairs of the predator for twenty-five days. Petri dishes were checked for eggs three times each day. Pairs were transferred to new Petri dishes at each check when eggs were found, and the eggs were counted. All females survived for the full twenty-five days, but two males (one each for the weevil and weevil + sugar diets) died during this period and were replaced with males of similar age.

On the twenty-sixth day of the experiment, a diet switch was instituted for those pairs that had previously fed on weevils and/or sugar, such that all pairs were now provided a diet of pea aphids (i.e., no weevils or sugar were provided to any of the pairs from this point on). The number of eggs produced on each day by individual females (i.e., females that had formerly dif- fered in diet but now shared a common diet) was determined for twelve days following the diet switch, during which time all pairs received aphids in excess. Four females (two from the sugar diet, and one each from the weevil and weevil + sugar diets) and three males (two from the weevil + sugar diet, and one from the weevil diet) died during the twelve days following the switch in diet. Males were replaced (again, with males of similar age) but females were not; data from females that died were not included in analyses for this part of the experiment.

Live body weights of females were measured three times during the experiment: at the outset (i.e., day 0), just prior to the switch in diet (i.e., day 25), and twelve days after the diet switch was instituted [i.e., day $37=$ day (12)]. Weights were determined to the nearest $0.1 \mathrm{mg}$.

One-way analysis of variance (ANOVA; SAS 2002) was used to compare the number of days on which females produced eggs, means for individual females for the number of eggs produced on those days, and the total number of eggs produced by females maintained on different diets during the first twentyfive days of the experiment. Repeated measures ANOVA was used to compare initial weights of individual females with their weights after twenty-five days on differing diets. One-way ANOVA was used to compare among treatments the number of days that elapsed before a female laid her first batch of eggs after being switched (on the twenty-sixth day) to an aphid diet, and number of eggs laid during the period following the switch in diet. One-way ANOVA was also used to compare final weights (twelve days after the switch in diet) among the four groups of females.

\section{Consumption rates of aphids and weevil larvae}

Four experiments were conducted to determine the quantity of aphids and alfalfa weevil larvae consumed in $24 \mathrm{~h}$ by adults of $H$. axyridis. Field collected adults were used in these experiments. The adults were maintained on a diet of pea aphids for up to several weeks as mixed-sex groups in Petri dishes $(15 \mathrm{~cm}$ diameter) held in an incubator at $12^{\circ} \mathrm{C}$ and $16 \mathrm{~L}: 8 \mathrm{D}$. One week prior to experimental use, they were transferred to an incubator at $20^{\circ} \mathrm{C}$ and $16 \mathrm{~L}: 8 \mathrm{D}$ and provided with an excess supply of both pea aphids and alfalfa weevil larvae (mixed instars).

In the first experiment, females and males were placed as solitary individuals in Petri dishes and held without prey for 24 $\mathrm{h}$ prior to the start of the experiment (both during this time and during the experiment, individuals continued to be held at $20^{\circ} \mathrm{C}$ and $16 \mathrm{~L}: 8 \mathrm{D}$ ). Individual adults were then randomly assigned to be transferred to another Petri dish (diameter, $9 \mathrm{~cm}$ ) stocked with either 40 adult pea aphids or 20 fourth instars of the alfalfa weevil (the experiment was completed in two blocks, with five and thirteen individuals of each sex tested for each prey species in the first and second blocks).

The wet weight of aphids or weevils provided to the predators was measured at the outset (to the nearest $0.1 \mathrm{mg}$ ). In addition, both wet and dry weights were measured for twelve additional sets each of 40 adult aphids and of 20 fourth instar weevils (all dry weights in the four experiments described here were obtained by placing material in a drying oven at $50^{\circ} \mathrm{C}$ for $48 \mathrm{~h}$ ). The mean ratio of the two weights for each set of prey was used as an estimate of percent dry weight of individuals of each prey species. This estimate $(22.7 \%$ for aphids, and $28.3 \%$ for weevil larvae) was then used to determine the dry weight of prey provided to each predator in the experiment.

Twenty-four hours after being placed with the prey, the predators were removed from the Petri dishes, and the remaining dry weight of prey (including partially consumed prey) in the dishes was measured. To determine the dry weight of prey consumed by the predators, two adjustments were made 
to the remaining dry weight of prey before subtracting it from the dry weight of prey provided. First, an adjustment was made for the estimated loss in weight of surviving prey due to their own metabolism (and activity). This adjustment was made by comparing dry weights of twelve additional sets of 20 fourth instar weevils or 40 adult aphids: six sets were dried and weighed immediately at the outset while the other six sets were dried and weighed after being held as above but without predators for $24 \mathrm{~h}$. From the set of prey held without predators, a second adjustment was made for the dry weight of frass voided by weevils during the $24 \mathrm{~h}$ experimental period (this frass remained in the Petri dishes when weevils were removed at the end of the experiment; aphids lost negligible amounts of dry weight in depositing honeydew during the experiment).

The second experiment was conducted in identical fashion to the first, except that only females of the predator were used (eighteen females in two blocks of nine were tested for each of the two prey species). For estimating the mg dry weight of prey consumed by predators, the percent dry weight of prey was calculated from an additional eight sets of both 20 fourth instars of the alfalfa weevil and 40 adult pea aphids. An additional element in the second experiment is that the dry weight $(\mathrm{mg})$ of predator frass produced during the $24 \mathrm{~h}$ in which the predator was placed with the prey was also measured (this was done by measuring all frass produced in $24 \mathrm{~h}$, and subtracting the estimated amount of this frass that was voided by weevil larvae).

The third experiment was of the same basic design as the first two experiments, but included two new elements as described below. Ten females each were provided with aphids or weevils. The percent dry weight of prey was calculated from an additional three sets of both 20 fourth instars of the alfalfa weevil and 40 adult pea aphids. During five one-hour periods throughout the twenty-four hours that predator and prey were together, the behaviors of the ladybird females were recorded. During each period, each female was scored 20 times at threeminute intervals as to whether or not she was actively searching (i.e., moving) or consuming prey. As in the second experiment, the dry weight $(\mathrm{mg})$ of predator frass produced during the $24 \mathrm{~h}$ in which the predator was placed with the prey was measured. Upon removal from the prey, the predator was transferred to a clean Petri dish without food or water for an additional $72 \mathrm{~h}$ (to allow the predator to clear her gut; e.g., see Honěk, 1986). The dry weight of frass produced by the predator during this $72 \mathrm{~h}$ period was also determined.

The basic design of the fourth experiment was the same as that of the third, except that only weevils were provided as prey. Half of the females were provided weevils (20 fourth instars) plus a vial of sugar water $(15 \%$ sucrose solution, as in the experiment above to measure rates of egg production). The remaining females were provided weevils plus a vial of water only. Frass production by the females was measured during the $24 \mathrm{~h}$ period in which they were placed with prey. The experiment was completed in two blocks (of thirteen and eight females for each of the two treatments). During three one-hour periods for the first block, and during five such periods for the second block, the behaviors of the ladybird females were scored as in the third experiment to measure the percentage of time that females searched actively or consumed weevils (instances were also noted in which females were observed drinking).

The dry weight of food consumed in $24 \mathrm{~h}$ by individual predators eating aphids or weevils was compared by ANOVA. In the first experiment, a two-way ANOVA (sex of predator $\times$ species of prey, with blocking) was performed, while in the second, third and fourth experiments, one-way ANOVA (species of prey, or presence/absence of sugar, with blocking) was performed (similar analyses were also performed for the quantity of frass produced). The activity patterns of females were compared between treatments in the third and fourth experiments by combining results from individual hours of observation. One-way ANOVA was used to compare the percent of time (following arcsine transformation) that females were observed actively searching, consuming prey, or drinking (in the fourth experiment).

\section{RESULTS}

\section{Egg production on differing diets}

Females of $H$. axyridis that were provided with weevil larvae or sugar alone for twenty-five days produced no eggs during this period. In contrast, females that were provided aphids began producing eggs on the seventh day, and thereafter produced a mean of 27 eggs per day through the twenty-fifth day (Fig. 1). Females maintained on a diet of weevil larvae plus sugar began laying eggs on the tenth day, producing a mean of five eggs per day thereafter (Fig. 1). In comparison with females maintained on a diet of aphids, females maintained on a diet of weevils plus sugar produced eggs on fewer days $[\bar{x}(\mathrm{SE})=$ 3.3 (1.2) versus 17.0 (0.5) days; $\left.\mathrm{F}_{1,14}=104.3, \mathrm{P}<0.0001\right]$, and tended to produce fewer eggs on those egg-laying days $\left[\bar{x}(\mathrm{SE})=19.1\right.$ (5.0) versus 30.6 (3.8) eggs; $\mathrm{F}_{1,12}=$ $3.48, \mathrm{P}=0.087]$. Overall, females that fed on weevils plus sugar produced only $15 \%$ as many eggs over the twenty-five day period as females that fed on aphids $[\bar{x}=$ 76.5 (SE: 36.6) vs 508.5 (SE: 47.7) eggs; $F_{1,14}=51.6, P$ $<0.0001]$.

Females maintained on the four diets differed in the amount of weight that they gained over the initial experimental period of twenty-five days (Fig. 2; repeated measures ANOVA for weights on days 0 and 25, interaction of time and treatment: $\left.\mathrm{F}_{3,27}=31.08, \mathrm{P}<0.0001\right)$. Females maintained on a diet of aphids gained most weight, followed by females maintained on a diet of weevils plus sugar. Females maintained on a diet of weevils gained only modest weight, while females maintained on a diet

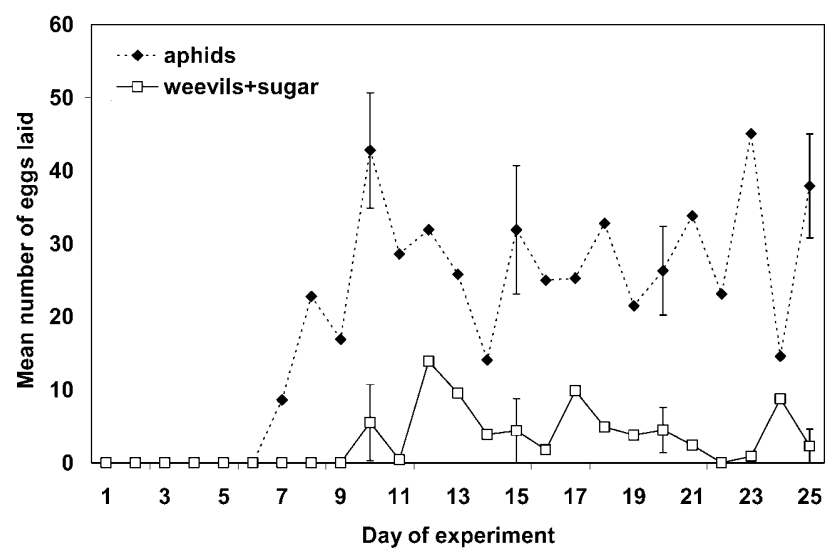

Fig. 1. The mean number of eggs laid each day by a recently molted female of $H$. axyridis after the female was placed (on "Day 0") on a diet of pea aphids or alfalfa weevil larvae plus sugar water ( $\mathrm{N}=8$ females per diet; note: other females placed on a diet of weevil larvae or sugar water alone laid no eggs during the experimental period of twenty-five days). Standard error bars (+/- one SE) are included for every fifth day of the experiment. 


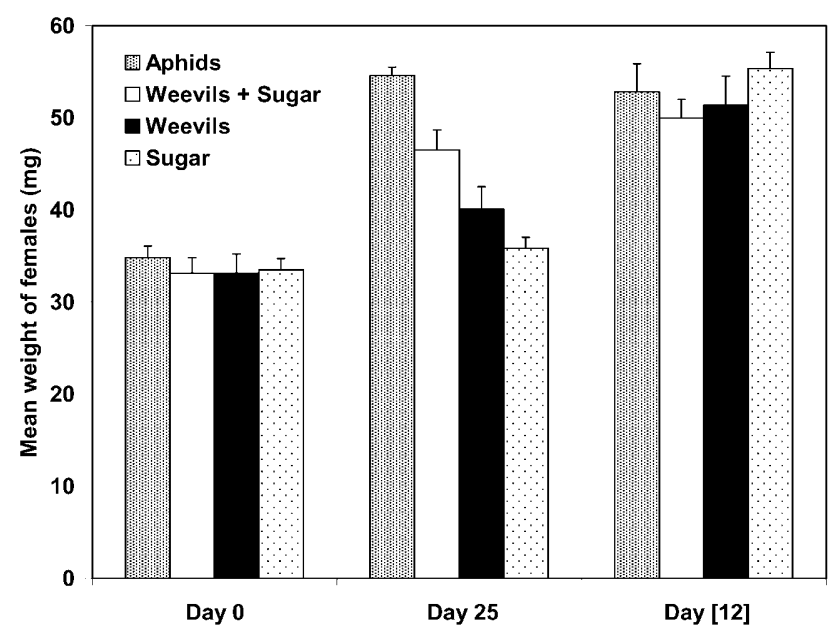

Fig. 2. Mean wet weights of females of $H$. axyridis immediately before being placed on diets of pea aphids, alfalfa weevil larvae and sugar water, or weevil larvae or sugar water alone (i.e., weights on "Day 0"); after being placed on these diets for twenty-five days (i.e., weights on "Day 25"); and after being maintained thereafter for twelve additional days on a diet of aphids [i.e., weights on "Day (12)"]. $\mathrm{N}=8$ females per diet [except on Day (12), when $\mathrm{N}=7$ for females initially provided with weevils only or with weevils and sugar, and $\mathrm{N}=6$ for females initially provided with sugar only].
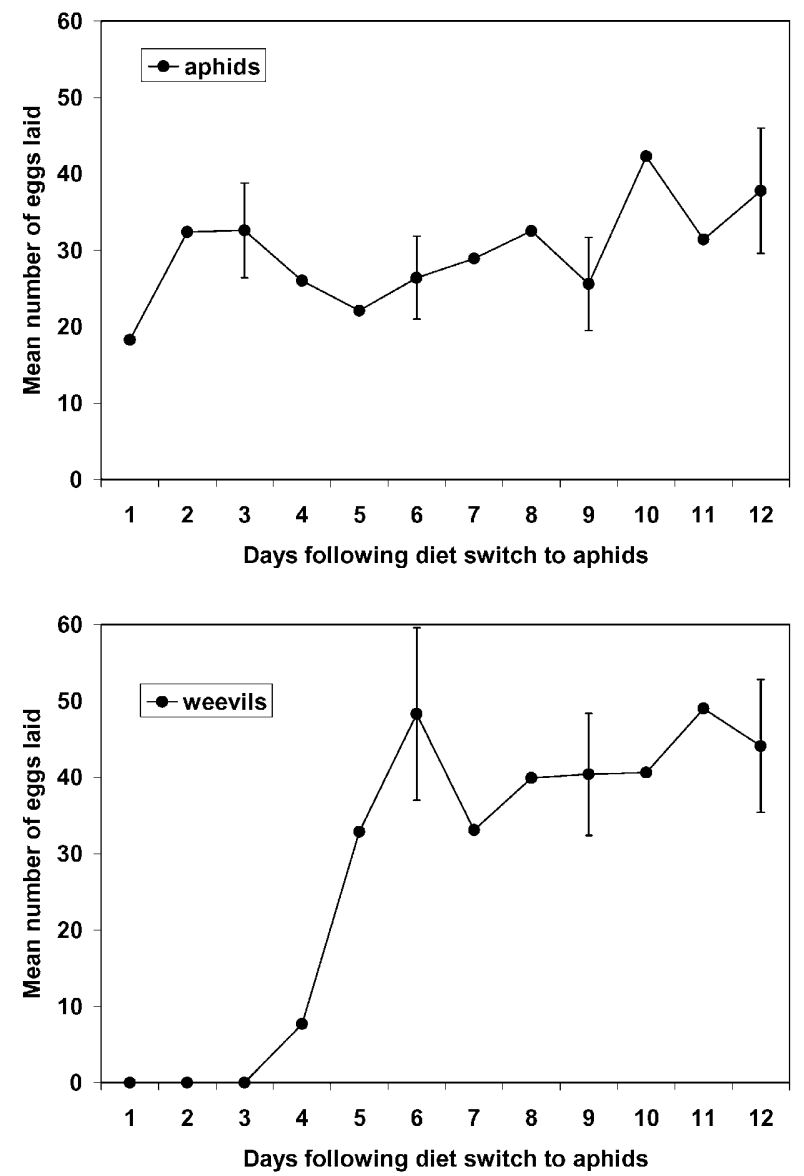

of sugar alone changed little in weight from day 0 to day 25.

Within three days of being switched (on the twentysixth day) to a diet of aphids, females maintained previously on a diet of weevils plus sugar began laying as many eggs as females that had fed from day 0 on aphids (Fig. 3). Females that had been provided with only weevils or only sugar also began laying eggs when switched to an aphid diet, but were slower to do so. Females that had fed on only weevils began laying eggs on the fourth day following the switch in diet to aphids; by the fifth day, they were laying as many eggs as females that had fed initially on aphids or weevils plus sugar (Fig. 3). Females that had fed on only sugar were slowest to initiate egg-laying, and thereafter only slowly approached the egg-laying rates of the other three groups of females (Fig. 3; ANOVA for the delay in days after diet switch until a female in each of the three treatments laid eggs: $\left.\mathrm{F}_{2,17}=17.55, \mathrm{P}<0.0001\right)$. From the sixth day on after the switch to an aphid diet, females that had fed previously on sugar alone produced only $58 \%$ as many eggs as females that had fed on aphids from the outset (Fig. 3; $\left.F_{1,12}=10.40, P=0.007\right)$. In contrast, females that had fed previously on weevils (with or without sugar) produced more eggs (121\% and 131\%) during this period than did
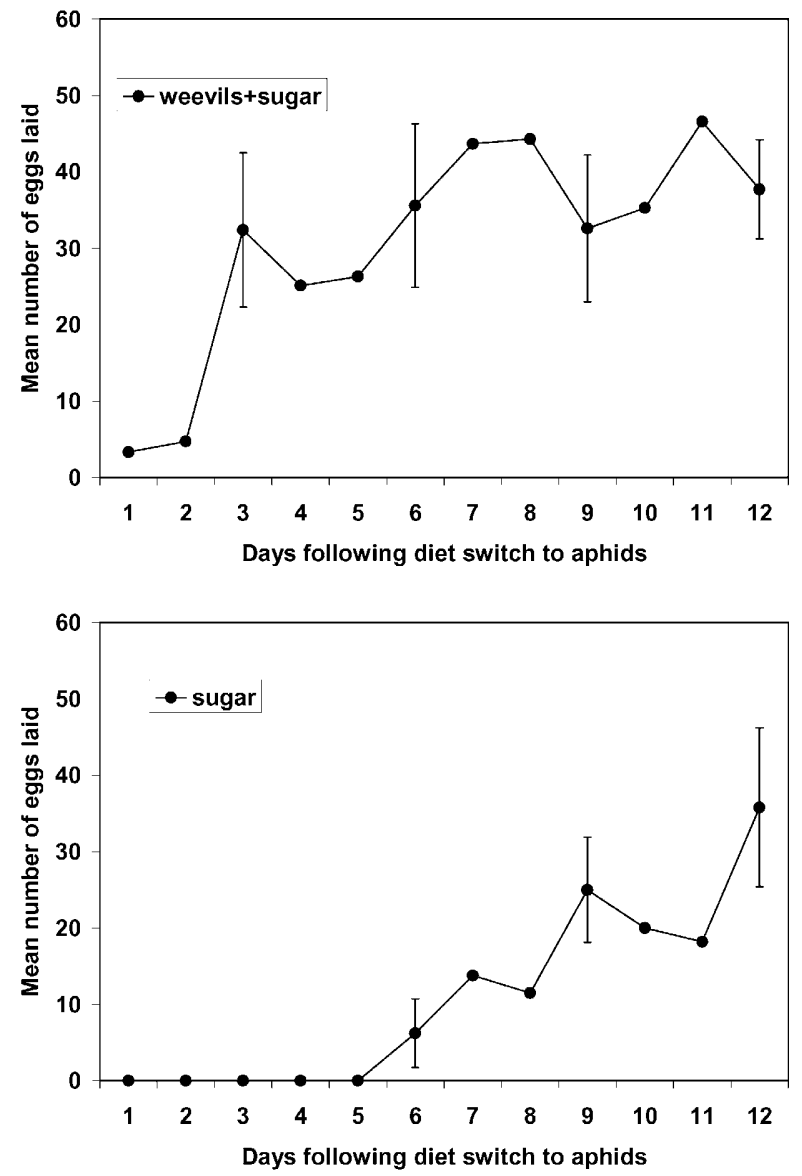

Fig. 3. The mean number of eggs laid each day by a female of $H$. axyridis when provided with pea aphids for twelve days after being maintained initially for twenty-five days on a diet of pea aphids (upper left), alfalfa weevil larvae plus sugar water (upper right), or weevil larvae or sugar water alone (lower left and right, respectively). $\mathrm{N}=8$ for females provided initially with aphids, $\mathrm{N}=$ 7 for females initially provided with weevils only or with weevils and sugar, and $\mathrm{N}=6$ for females initially provided with sugar only. Standard error bars (+/- one SE) are included for every third day of the experiment. 
TABLE 1. Mean (standard error) dry weight (mg) of pea aphids or alfalfa weevil larvae consumed by an adult of $H$. axyridis, and mean dry weight $(\mathrm{mg})$ of frass produced by the female, when provided with an excess supply of aphids or weevils for $24 \mathrm{~h}$.

\begin{tabular}{|c|c|c|c|c|c|}
\hline \multirow{2}{*}{ Experiment } & \multirow{2}{*}{$\begin{array}{c}\text { Sex of } \\
\text { predator }\end{array} \mathrm{N}^{1}$} & \multicolumn{2}{|c|}{ Consumed (mg) } & \multicolumn{2}{|c|}{ Frass produced $(\mathrm{mg})^{2}$} \\
\hline & & Aphids & Weevils & & \\
\hline \multirow[t]{2}{*}{ First } & & & & & \\
\hline & s 18 & & & - & - \\
\hline Second & Females 18 & $6.1(0.3)$ & $2.8(0.4)$ & $2.4(0.3)$ & $2.5(0.3)$ \\
\hline Third & Females 10 & $9.1(0.5)$ & $4.3(0.4)$ & $5.7(0.2)$ & $3.8(0.2)$ \\
\hline
\end{tabular}

${ }^{1} \mathrm{~N}$ - number of individuals per treatment (i.e., aphid or weevil diet) $;{ }^{2} \mathrm{mg}$ frass produced in $24 \mathrm{~h}$ (second experiment) or $24+$ $72 \mathrm{~h}$ (third experiment).

females that fed on aphids from the outset (Fig. 3; ANOVA with linear contrast for aphid diet versus diets with weevils: $\mathrm{F}_{1,19}=4.11, \mathrm{P}=0.057$ ).

By the conclusion of the experiment (twelve days after the switch to aphid diet), weights of females in all four groups were very similar to weights on day 25 of females that had fed on aphids since the outset (Fig. 2; ANOVA for weights of the four groups of females at the conclusion of the experiment: $\mathrm{F}_{3,25}=0.71, \mathrm{P}=0.55$ ).

\section{Consumption rates of aphids and weevil larvae}

In the first experiment, females consumed significantly more biomass of both prey species than did males, and both sexes ate significantly more dry weight of aphids than they did of weevils (Table 1; two-way ANOVA: sex of predator $\mathrm{F}_{1,67}=52.56, \mathrm{P}<0.0001$; species of prey $\mathrm{F}_{1,67}$ $=30.28, \mathrm{P}<0.0001$; interaction between sex of predator and species of prey $\mathrm{F}_{1,67}=0.50, \mathrm{P}=0.48$ ).

In the second and third experiments (in which only females were offered either aphids or weevils), females again ate more (approximately twice as much) dry weight of aphids than of weevils (Table 1; one-way ANOVA for second experiment: $F_{1,33}=43.99, P<0.0001$; for third experiment: $\left.F_{1,18}=50.17, P<0.0001\right)$. Females produced similar amounts of frass during the $24 \mathrm{~h}$ that they were placed with weevil larvae versus aphids in the second experiment (Table 1; one-way ANOVA: $\mathrm{F}_{1,32}=0.03, \mathrm{P}=$ $0.87)$. Frass production by females on a weevil diet thus represented a higher percentage $(90 \%)$ of the dry weight of prey consumed than it did on a diet of aphids $(40 \%)$. In the third experiment, females produced significantly less frass on a weevil versus aphid diet during the $24 \mathrm{~h}$ when held with prey plus the next $72 \mathrm{~h}$ when held without prey (Table 1; one-way ANOVA: $\mathrm{F}_{1,18}=39.79, \mathrm{P}<0.0001$ ). As in the second experiment, however, the dry weight of frass produced by females on a weevil diet represented a higher percentage $(89 \%)$ than it did on a diet of aphids $(62 \%)$.

In the third experiment, females were observed searching much less frequently in the presence of aphids than in the presence of weevil larvae [13.5\% (SE: 1.9) versus $41.6 \%$ (SE: 5.2 ) of observations; one-way ANOVA on percentages following arcsine transformation: $\mathrm{F}_{1,18}=28.86, \mathrm{P}<0.0001$ ). In addition to spending more time immobile, females were observed more frequently to consume aphids versus weevils $[8.7 \%$ (SE: 1.1 ) vs $2.0 \%$ (SE: 0.8 ) of observations; one-way ANOVA on percentages following arcsine transformation: $\mathrm{F}_{1,18}=25.52, \mathrm{P}<0.0001$ ).

The fourth experiment compared females' consumption rates on diets of weevil larvae plus sugar water versus weevil larvae plus water only. Females with versus without access to sugar did not differ significantly in their consumption rates of weevils $[\bar{x}(\mathrm{SE})=1.1(0.7)$ vs. 1.2 (0.5) $\mathrm{mg}$ dry weight consumed in $24 \mathrm{~h}$; one-way ANOVA: $\mathrm{F}_{1,39}=0.01, \mathrm{P}=0.93$ ]. They also did not differ in their rates of frass production $[\bar{x}(\mathrm{SE})=0.6(0.2)$ vs. 0.7 $(0.1) \mathrm{mg}$ dry weight produced in $24 \mathrm{~h}$; one-way ANOVA: $\left.\mathrm{F}_{1,39}=0.74, \mathrm{P}=0.40\right]$. Females with and without access to sugar spent similar amounts of time consuming weevils [2.7\% (SE: 1.6 ) versus $3.3 \%$ (SE: 1.9) of observations; one-way ANOVA on percentages following arcsine transformation: $\left.F_{1,39}=0.001, P=0.97\right]$. Females without access to sugar, however, spent more time searching actively than did females with access to sugar $[37.6 \%$ (SE: 3.8) versus $24.8 \%$ (SE: 4.5) of observations; one-way ANOVA on percentages following arcsine transformation: $\left.F_{1,39}=4.37, P=0.043\right]$. Females only infrequently drank water without sugar but spent large amounts of time drinking sugar water $[0.2 \%$ (SE 0.1) versus $33.0 \%$ (S.E.: 6.3) of observations; one-way ANOVA on percentages following arcsine transformation: $\left.\mathrm{F}_{1,39}=40.92, \mathrm{P}<0.0001\right]$.

\section{DISCUSSION}

The suitability of pea aphids versus alfalfa weevil larvae in support of egg production by $H$. axyridis illustrates well the distinction between essential and alternative foods drawn by Hodek (Hodek, 1962; Hodek \& Honěk, 1996), and between nursery and food prey drawn by Dixon (2000). Thus, only on a diet of aphids in the present study did females of $H$. axyridis lay eggs in large numbers. Females laid no eggs on diets of weevils or sugar alone, and laid only small numbers of eggs when these two foods were provided together. The value of weevil larvae as alternative or food prey for $H$. axyridis females is apparent when one considers the predator's reproductive response upon a diet switch from weevils to aphids. Upon the switch in diet, females that had fed previously on weevils produced eggs sooner and laid many more eggs in the days thereafter than did females that had previously fed on sugar (and were then also switched to an aphid diet). Thus, the availability of weevils in the absence of aphids enabled these females to better maintain themselves (e.g., as reflected in their body weights) than females that had access only to sugar, thereby realizing a large "pay-off" in reproductive output once aphids became available.

A number of factors may determine proximately the degree to which prey such as weevils or aphids may serve as alternative or essential foods in support of reproduction for $H$. axyridis. These factors include how readily the predator consumes the prey (e.g., Bilde \& Toft, 1994), 
how well the predator can assimilate the prey and how nutritious the assimilated prey material is (e.g., Wipperfürth et al., 1987; Bilde \& Toft, 1999; Bilde et al., 2000), and how much the predator then allocates of what is assimilated to reproductive effort versus other uses (e.g., O’Neil \& Wiedenmann, 1987; Legaspi \& O’Neil, 1993; Nakashima \& Hirose, 1999; Vivan et al., 2003). Our feeding studies of $H$. axyridis females provide some insights into the likely importance of some of these factors. In each of the experiments, the predators consumed significantly more (overall, about twice as much) dry weight of aphids than of weevils in $24 \mathrm{~h}$ (given that the percent moisture content of live aphids was higher than that of weevils, the predators also consumed more wet weight of the former). Furthermore, less frass was produced by $H$. axyridis females in comparison to the quantity of aphids versus weevils consumed; thus, the predators appear able to assimilate a greater proportion of the amount of aphids versus weevils consumed (it is difficult, however, to compare the nutritional value of the amounts of aphids and weevils that the predators were able to assimilate). Finally, the predators engaged much more in the relatively "costly" behavior of searching actively when weevils versus aphids were present, thereby diverting more nutrients and energy away from egg production. Previous studies have also shown aphidophagous ladybird females to be more active when aphids are absent than when these preferred prey are present (e.g., Frazer \& Gill, 1981; Evans \& Dixon, 1986; Nakamuta, 1987). Thus, lower rates of food intake, assimilation, and nutrient/energy allocation to reproduction all appear to contribute (perhaps along with additional factors such as relatively low intrinsic nutritional quality and/or metabolic costs of detoxification) to the striking difference in rates of egg production by females of $H$. axyridis maintained on diets of the alternative prey, alfalfa weevils, versus the essential prey, pea aphids.

The modest egg production by $H$. axyridis females maintained on a diet of both weevils and sugar is noteworthy. The relative rate of egg production by these females on this diet versus a diet of pea aphids is similar to rates previously recorded for two other aphidophagous ladybird species that inhabit Utah alfalfa fields along with H. axyridis, Coccinella transversoguttata richarsoni Brown and C. septempunctata L. (Richards \& Evans, 1998; Evans et al., 1999). For several reasons, we had expected females of $H$. axyridis to lay eggs more readily on a diet of weevils or weevils and sugar than do females of these other species. First, H. axyridis appears to be less specialized in its behavior as a predator of aphids in particular than are the two Coccinella spp. (e.g., see Yasuda \& Ohnuma, 1999; Kalaskar \& Evans, 2001). Secondly, natural populations of close relatives of $H$. axyridis have been reported to exploit beetle larvae as their principal prey (e.g., Whitehead \& Duffield, 1982; Elliott \& de Little, 1990). Finally, females of $H$. axyridis reproduce well on other non-aphid foods [powder of drone honey bees (Niijima et al., 1988) and eggs of Lepidoptera (Schanderl et al., 1988; Abdel-Salam \& Abdel-Baky, 2001; Michaud, 2002)].

Larvae of $H$. axyridis (and C. septempunctata) are less able to survive and develop on a diet of alfalfa weevil larvae than on a diet of pea aphids (Kalaskar \& Evans, 2001). The failure of $H$. axyridis females to reproduce more readily when consuming weevils may therefore reflect the inadequacy of these prey as food for the females' offspring. Females may exploit alfalfa weevils as alternative prey quite effectively, however, in poising themselves for future reproduction when they encounter essential or nursery prey such as aphids. In this way, weevils may serve a role similar to that of food sprays for entomophagous insects applied to crops early in the build-up of an aphid population (e.g., Schiefelbein \& Chiang, 1966; Hagen et al., 1971).

As has been found in other studies of mixed diets for predators (e.g., Bilde \& Toft, 1994, 1999), the dietary combination of weevils and sugar was superior to diets of either food alone in supporting maintenance and reproduction of $H$. axyridis females. Our feeding studies suggest that the difference does not result from a positive effect of sugar consumption on rates of either weevil consumption or assimilation by these predators. On the other hand, the overall nutrient and energy intake of females with access to sugar as well as weevils appeared greater (i.e., they spent large amounts of time drinking sugar water while consuming amounts of weevil larvae similar to the amounts consumed by females without access to sugar). Females with access to sugar also spent less time (and energy/nutrients) actively searching. These two factors (more intake overall of nutrients and energy, and fewer nutrients and less energy expended in active search) may contribute to the enhanced reproductive performance of the predators associated with the mixed diet. Whether other factors are also involved (e.g., a synergistic effect of sucrose in abundance when mixed with weevil nutrients; see Wheeler, 1996; England \& Evans, 1997) remains to be investigated further.

Dixon's (2000) concept of nursery prey captures well the key idea that the distinction between alternative and essential foods often reflects that predatory insects, in their linkage of feeding and reproductive behavior, are likely quite carefully adapted to confront the challenging prey environment that they face. Thus, in nature, these predators often face shortage of suitable prey, not only for themselves (e.g., Lenski, 1984; Siddique \& Chapman, 1987; Beckman \& Hurd, 2003) but perhaps even more so for their offspring (e.g., Dixon, 1970; Wratten, 1973). Most appear to respond both by favoring selfmaintenance over reproduction when food is limited (e.g., O’Neil \& Wiedenmann, 1987; Legaspi \& O’Neil, 1993), and by consuming a large variety of prey types. Given such apparent polyphagy, it is indeed intriguing to consider the degree to which predatory insects may be adapted further to respond in their reproductive effort to particular kinds of prey. Thus, as suggested by Hodek's (1962; Hodek \& Honěk, 1996) distinction between essential and alternative prey, they may be stimulated to initiate 
or greatly increase reproductive effort not simply by sufficient current availability of food in general, but rather by the presence and consumption of key nursery prey that are likely to sustain the development of their offspring (e.g., Evans \& Dixon, 1986; Wipperfürth et al., 1987; Spieles \& Horn, 1998; Sadeghi \& Gilbert, 2000). In their reproductive response to aphids versus other prey such as the alfalfa weevil, aphidophagous ladybirds appear excellent candidates with which to pursue this general hypothesis further. In shedding some light on how consumption of the alfalfa weevil is linked to reproductive activity in $H$. axyridis, the experimental results reported here provide some foundation with which to explore further the hypothesis of an adaptive basis that may underlie the distinction between essential and alternative prey for $H$. axyridis and other similar predators.

ACKNOWLEDGEMENTS. This paper was prepared in honor of K.S. Hagen, whose research and enthusiasm led to its genesis. We thank L. Croft, N. Davidson, M. Johnson, Y. Kajita, A. Kalaskar, A. Nelson, and C. Simons for their assistance in rearing aphids, collecting weevils, and conducting the experiments. We also thank two anonymous reviewers for their helpful comments on the manuscript. Financial support was provided by the USDA-NRI (99-35302-8104) and the Utah Agricultural Experiment Station.

\section{REFERENCES}

Abdel-Salam A.H. \& ABdel-BaKy N.F. 2001: Life table and biological studies of Harmonia axyridis Pallas (Col., Coccinellidae) reared on the grain moth eggs of Sitotroga cerealella Olivier (Lep., Gelechiidae). J. Appl. Entomol. 125: 455-462.

BeCK J.B. \& ToFt S. 2000: Artificial selection for aphid tolerance in the polyphagous predator Lepthyphantes tenuis. $J$. Appl. Ecol. 37: 547-556.

Beckman N. \& Hurd L.E. 2003: Pollen feeding and fitness in praying mantids: the vegetarian side of a tritrophic predator. Environ. Entomol. 32: 881-885.

BILDE T. \& ToFT S. 1994: Prey preference and egg production of the carabid beetle Agonum dorsale. Entomol. Exp. Appl. 73: 151-156.

BILDE T. \& TofT S. 1999: Prey consumption and fecundity of the carabid beetle Calathus melanocephalus on diets of three cereal aphids: high consumption rates of low-quality prey. Pedobiologia 43: 422-429.

Bilde T., Axelsen J.A. \& Toft S. 2000: The value of Collembola from agricultural soils as food for a generalist predator. J. Appl. Ecol. 37: 672-683.

Blackman R.L. 1967: The effects of different aphid foods on Adalia bipunctata L. and Coccinella 7-punctata L. Ann. Appl. Biol. 59: 207-219.

Dixon A.F.G. 1970: Factors limiting the effectiveness of the coccinellid beetle, Adalia bipunctata (L.), as a predator of the sycamore aphid, Drepanosiphum platanoides (Schr.). J. Anim. Ecol. 39: 739-751.

Dixon A.F.G. 2000: Insect Predator-Prey Dynamics. Ladybird Beetles and Biological Control. Cambridge University Press, Cambridge, UK, ix $+257 \mathrm{pp}$.

Elliott H.J. \& De Little D.W. 1980: Laboratory studies on predation of Chrysophtharta bimaculata (Olivier) (Coleoptera: Chrysomelidae) eggs by the coccinellids Cleobara mellyi Mulsant and Harmonia conformis (Boisduval). Gener. Appl. Entomol. 12: 33-36.
England S. \& Evans E.W. 1997: Effects of pea aphid (Homoptera: Aphididae) honeydew on longevity and fecundity of the alfalfa weevil (Coleoptera: Curculionidae) parasitoid Bathyplectes curculionis (Hymenoptera: Ichneumonidae). Environ. Entomol. 26: 1437-1441.

Evans E.W. 2004: Habitat displacement of North American ladybirds by an introduced species. Ecology 85: 637-647.

Evans E.W. \& Dixon A.F.G. 1986: Cues for oviposition by ladybird beetles (Coccinellidae): response to aphids. J. Anim. Ecol. 55: 1027-1034.

Evans E.W. \& England S. 1996: Indirect interactions in biological control of insects: pests and natural enemies in alfalfa. Ecol. Appl. 6: 920-930.

Evans E.W., Stevenson A.T. \& Richards D.R. 1999: Essential versus alternative foods of insect predators: benefits of a mixed diet. Oecologia 121: 107-112.

Evans E.W., Richards D.R. \& Kalaskar A. 2004: Using food for different purposes: female responses to prey in the predator Coccinella septempunctata L. (Coleoptera: Coccinellidae). Ecol. Entomol. 29: 27-34.

Francis F., Haubruge E., Hastir P. \& Gaspar C. 2001: Effect of aphid host plant on development and reproduction of the third trophic level, the predator Adalia bipunctata (Coleoptera: Coccinellidae). Environ. Entomol. 30: 947-952.

Frazer B.D. \& Gill B. 1981: Hunger, movement, and predation of Coccinella californica on pea aphids in the laboratory and in the field. Can. Entomol. 113: 1025-1033.

Hagen K.S., Sawall JR. E.F. \& Tassan R.L. 1971: The use of food sprays to increase effectiveness of entomophagous insects. Proc. Tall Timbers Conf. Ecol. Anim. Control Habitat Manag. 3: 59-81.

Hagen K.S., Mills N.J., Gordh G. \& McMurtry J.A. 1999: Terrestrial arthropod predators of insect and mite pests. In Bellows T.S. \& Fisher T.W. (eds): Handbook of Biological Control. Principles and Applications of Biological Control. Academic Press, San Diego, CA, pp. 383-503.

Hoder I. 1962: Essential and alternative food in insects. In Strouhal H. \& Beier M. (eds): Transactions of the XIth International Congress of Entomology. Vol. 2. Organisationalskomittee des XI Internationalen Kongress für Entomologie, Vienna, pp. 697-698.

Hodek I. \& HonĚK A. 1996: Ecology of Coccinellidae. Kluwer Academic Publishers, Dordrecht, 464 pp.

HoNĚK A. 1986: Production of faeces in natural populations of coccinellids (Col.) and estimation of predation rates. J. Appl. Entomol. 102: 467-476.

Kalaskar A. \& Evans E.W. 2001: Larval responses of aphidophagous lady beetles (Coleoptera: Coccinellidae) to weevil larvae versus aphids as prey. Ann. Entomol. Soc. Am. 94: $76-81$.

Kосн R.L. 2003: The multicolored Asian lady beetle, Harmonia axyridis: a review of its biology, uses in biological control, and non-target impacts. J. Insect Sci. 3: 32, 16 pp. (available online: insectscience.org/3.32)

Legaspi J.C. \& O'NeIL R.J. 1993: Life history of Podisus maculiventris given low numbers of Epilachna varivestis as prey. Environ. Entomol. 22: 1192-1200.

LENSKI R.E. 1984: Food limitation and competition: a field experiment with two Carabus species. J. Anim. Ecol. 53: 203-216.

Michaud J.P. 2002: Invasion of the Florida citrus ecosystem by Harmonia axyridis (Coleoptera: Coccinellidae) and asymmetric competition with a native species, Cycloneda sanguinea. Environ. Entomol. 31: 827-835.

NaJima K., MatsuKa M. \& OKada I. 1986: Artificial diets for an aphidophagous coccinellid, Harmonia axyridis, and its 
nutrition. In Hodek I. (ed.): Ecology of Aphidophaga. Academia, Prague \& Dr. W. Junk, Dordrecht, pp. 37-50.

NaKamuta K. 1984: Aphid body fluid stimulates feeding of a predatory ladybeetle, Coccinella septempunctata L. (Coleoptera: Coccinellidae). Appl. Entomol. Zool. 19: 123-125.

NAKAMUTA K. 1987: Diel rhythmicity of prey-search activity and its predominance over starvation in the lady beetle, Coccinella septempunctata bruckii. Physiol. Entomol. 12: 91-98.

NaKashima Y. \& Hirose Y. 1999: Effects of prey availability on longevity, prey consumption, and egg production of the insect predators Orius sauteri and O. tantillus (Hemiptera: Anthocoridae). Ann. Entomol. Soc. Am. 92: 537-541.

O'NeIL R.J. \& WiedenManN R.N. 1987: Adaptations of arthropod predators to agricultural systems. Fla Entomol. 70: $40-48$.

RichaRDS D.R. \& Evans E.W. 1998: Reproductive responses of aphidophagous lady beetles (Coleoptera: Coccinellidae) to non-aphid diets: an example from alfalfa. Ann. Entomol. Soc. Am. 91: 632-640.

SAdeghi H. \& Gilbert F. 2000: The effect of egg load and host deprivation on oviposition behaviour in aphidophagous hoverflies. Ecol. Entomol. 25: 101-108.

Schanderl H., Ferran A. \& Garcia V. 1988: L'élevage de deux coccinelles Harmonia axyridis et Semiadalia undecimnotata à l'aide d'oeufs d'Anagasta kuehniella tués aux rayons ultraviolets. Entomol. Exp. Appl. 49: 235-244.

Schiefelbein J.W. \& Chiang H.C. 1966. Effects of spray of sucrose solution in a corn field on the populations of predatory insects and their prey. Entomophaga 11: 333-339.
Siddique A.B. \& Chapman R.B. 1987: Effect of prey type and quantity on the reproduction, development, and survival of Pacific damsel bug, Nabis kinbergii Reuter (Hemiptera: Nabidae). N. Z. J. Zool. 14: 343-349.

SPIELES D.J. \& HoRN D.J. 1998: The importance of prey for fecundity and behavior in the gypsy moth (Lepidoptera: Lymantriidae) predator Calosoma sycophanta (Coleoptera: Carabidae). Environ. Entomol. 27: 458-462.

Vivan L.M., Torres J.B. \& Veiga A.F.S.L. 2003: Development and reproduction of a predatory stinkbug, Podisus nigrispinus, in relation to two different prey types and environmental conditions. BioControl 48: 155-168.

WheELER D. 1996: The role of nourishment in oogenesis. Annu. Rev. Entomol. 41: 407-431.

WhiteHEAD D.R. \& DufField R.M. 1982: An unusual specialized predator prey association (Coleoptera: Coccinellidae, Chrysomelidae): failure of a chemical defense and possible practical application. Coleopt. Bull. 36: 96-97.

Wipperfürth T., Hagen K.S. \& Mittler T.E. 1987: Egg production by the coccinellid Hippodamia convergens fed on two morphs by the green peach aphid, Myzus persicae. Entomol. Exp. Appl. 44: 195-198.

WRATTEN S.D. 1973: The effectiveness of the coccinelid beetle, Adalia bipunctata (L.), as a predator of the lime aphid, Eucallipterus tiliae L. J. Anim. Ecol. 42: 785-802.

Yasuda H. \& OHNuma N. 1999: Effect of cannibalism and predation on the larval performance of two ladybird beetles. Entomol. Exp. Appl. 93: 63-67.

Received September 10, 2004; revised and accepted April 7, 2005 